\title{
ENTRE LA REVUELTA Y LA PANDEMIA: CONSTRUCCIÓN DE LAS JUVENTUDES CHILENAS DESDE LAS MIRADAS ACADÉMICAS Y CIENTÍFICAS
}

\author{
DIEGO ANIÑIR MANRÍQUEZ ${ }^{1}$ \\ ELIANÉ MARTÍNEZ DÍAZ ${ }^{2}$ \\ PAULINA CASTILLO ${ }^{3}$ \\ LEONARDO ALARCÓN ${ }^{4}$ \\ YADIRA PALENZUELA FUNDORA ${ }^{5}$ \\ Claudia CASTILla García ${ }^{6}$
}

\begin{abstract}
RESUMEN
Se presenta una revisión documental de la producción académica e institucional entre octubre 2019 y abril 2021 con relación a las juventudes chilenas durante la Revuelta y la Pandemia. Con ello, se busca generar conocimiento acerca de la construcción de las juventudes desde el saber académico e institucional con respecto a estos acontecimientos. El análisis se desarrolló a partir de tres categorías que se evidencian como centrales en esta producción: control social, acción política y afectividades. Finalizamos compartiendo algunas pistas analíticas y epistémicas que consideramos de relevancia para abordar las tensiones y reflexiones en torno a las juventudes en este momento de crisis.
\end{abstract}

PALABRAS ClAVES: ACCIÓN COLECTIVA, CONTROL SOCIAL, AFECTIVIDADES, JUVENTUDES.

\footnotetext{
${ }^{1}$ Sociólogo; Magister@ Estudios Latinoamericanos, Universidad de Chile. Integrante del Núcleo de Investigación y Acción en Juventudes, Universidad de Chile. Correo electrónico: diego.aninir@gmail.com

2 Antropóloga; Magister $\odot$ Ciencias Sociales Mención Sociología de la Modernización, Universidad de Chile. Integrante del Núcleo de Investigación y Acción en Juventudes, Universidad de Chile. Correo electrónico: eliane.dmartinezd@gmail.com

${ }^{3}$ Psicóloga; Magíster en Ciencias Sociales mención Sociología de la Modernización, Universidad de Chile. Doctora $\odot$ Universidad Autónoma de Barcelona. Integrante del grupo de Investigación Globalisation, Education and Social Policies, UAB. Núcleo de Investigación y Acción en Juventudes, Universidad de Chile. Correo electrónico: paulinacastillo.h@gmail.com

${ }^{4}$ Licenciado en Sociología, Universidad de Chile. Integrante del Núcleo de Investigación y Acción en Juventudes, Universidad de Chile. Correo electrónico: leonardo.alarcon.v@gmail.com

${ }^{5}$ Psicóloga y Máster en Psicología Educativa, Universidad de La Habana, Cuba. Magíster en Análisis Sistémico Aplicado a la Sociedad y Doctora en Psicología por la Universidad de Chile. Integrante del Núcleo de Investigación y Acción en Juventudes, Universidad de Chile y Miembro de GT Infancia y Juventudes de CLACSO. Correo electrónico: ypalenzuela@gmail.com

${ }^{6}$ Psicóloga; Máster en Teoría y Metodología de las Ciencias Sociales; Doctora en Ciencias Sociales. Integrante del Núcleo de Investigación y Acción en Juventudes, Universidad de Chile. Correo electrónico: claudiacastillagarcia@gmail.com
} 


\title{
ENTRE A REVOLTA E A PANDEMIA: CONSTRUÇÃO dAS JUVENTUDES CHILENAS A PARTIR DAS PERSPECTIVAS ACADÊMICAS E CIENTÍFICAS
}

\begin{abstract}
RESUMO
É apresentada uma análise documental da produção acadêmica e institucional entre outubro de 2019 e abril de 2021 em relação às juventudes chilenas durante a Revolta e a Pandemia. Com isto, procuramos gerar conhecimento sobre a construção das juventudes a partir do saber acadêmico e institucional em relação a estes eventos. A análise foi desenvolvida considerando 3 categorias que são evidenciadas como centrais nesta produção: controle social, ação política e afetividades. Concluímos compartilhando algumas pistas analíticas e epistêmicas que consideramos relevantes para abordar as tensões e reflexões sobre as juventudes neste momento de crise.
\end{abstract}

PALAVRAS-CHAVE: AÇÃO COLETIVA, CONTROLE SOCIAL, AFETIVIDADE, JUVENTUDES.

\section{Between the Social Revolt AND THE PANDEMIC: THE CONSTRUCTION OF CHILEAN YOUTHS FROM ACADEMIC AND SCIENTIFIC PERSPECTIVES}

\begin{abstract}
A documentary review of the academic and institutional production between October 2019 and April 2021 in relation to Chilean youths during the Social Revolt and the Covid-19 pandemic is presented in this article, aiming to generate knowledge about the construction of youths from the academic and institutional knowledge related to these events. The analysis was developed from 3 categories evidenced as central in this production: social control, political action, and affectivities. We conclude by sharing some analytical and epistemic clues that we consider relevant to address the tensions and reflections on youths at this time of crisis.
\end{abstract}

KEYWORDS: COLLECTIVE ACTION, SOCIAL CONTROL, AFFECTIVITIES, YOUTHS. 


\section{INTRODUCCIÓN}

La pandemia del Covid-19 llegó a Chile en un momento de excepción política $^{7}$, autodenominado como «estallido social» por el movimiento convergente y la prensa fundamentalmente, pero trabajado como «revuelta» por algunos autores (Karmy, 2019; Richard, 2020; Villalobos-Ruminot, 2020). Este momento político que se inició el 18 de octubre de 2019 consistió en la activación de múltiples movimientos, demandas - coyunturales y estructurales-y figuras de participación de diversos grupos etarios que develó el escenario de desigualdad estructural que el modelo económico instauró y que la institucionalidad política consagró.

Este momento de la revuelta se inició con los y las estudiantes como protagonistas, saltando torniquetes del metro subterráneo de Santiago en protesta al alza de 30 pesos del transporte público. Las manifestaciones pasaron de estar concentradas alrededor de las estaciones del metro a distribuirse como flujos con distintos nodos de acción en las poblaciones, en las ciudades y en las regiones. Confluyeron movimientos que tenían demandas diversas: sistema de previsiones, derecho a la vivienda, salud, educacionales, feministas, derechos territoriales, etc. Los manifestantes se multiplicaron, de jóvenes a adultos mayores, de adultos a niños, unidos tras las cacerolas y las barricadas, tomando el espacio público de sus territorios y teniendo como eje central, al menos en la Región Metropolitana, la Plaza de la Dignidad (ex Plaza Italia).

Si bien el movimiento careció de dirigencia que se aludiera la representación de aquellos flujos, tuvo una actoría por excelencia: los/as jóvenes. Estos/as potenciaron las jornadas de movilización política (Alè, Duarte y Miranda, 2020) que, a su vez, dieron paso a un «tiempo inaugural» (Richard,

\footnotetext{
${ }^{7}$ El 19 de octubre de 2019, tras el inicio de la revuelta, se declaraba en Chile estado de excepción constitucional de emergencia; en marzo, tras la llegada del Covid-19, se declaraba, a pocos meses del anterior, estado de excepción constitucional de catástrofe.
} 
2020) de ruptura con la institucionalidad tradicional, de fractura con el sistema de participación política, de crítica hacia el modelo económico neoliberal; de apertura del espacio público para el ejercicio de la acción colectiva, de articulación de distintos actores de estratos bajos y medios, de creciente organización territorial y de reafirmación de repertorios de protesta y de acción colectiva (Pincheira, 2020a).

Sin embargo, aquel tiempo de revuelta se quiebra con la irrupción de la pandemia. Esta no solo cambia el escenario de agitación, pasando del flujo incontrolado por las calles al control de las cuarentenas, sino que también modifica el discurso articulador sobre los y las jóvenes, pasando de agentes que deben asumir sus potencialidades de cambios a sujetos que deben gatillar autocuidados y aceptar su responsabilización en el aumento de contagios, al tiempo que sus prácticas sociales son criminalizadas y controladas por parte de las autoridades gubernamentales y la prensa (Escobar, Araya, Hernández y Duarte, 2021; Araya, Carrasco y Olivares, 2020).

Esta transición de la revuelta al confinamiento pandémico, en Chile, generó variados efectos a nivel de Estado en cuanto a políticas sociales, sanitarias y de seguridad. Asimismo, a nivel de la población en distintos ámbitos: sanitarios, laborales, educacionales, psico-emocionales-afectivos, securitarios y políticos, entre otros. Estos escenarios señalados como momentos de crisis han suscitado diversas descripciones y análisis por parte del saber académico e institucional, quienes se han volcado a realizar estudios de carácter teórico, cualitativo y estadísticos en los ámbitos anteriormente descritos.

A partir de ello y teniendo en cuenta el presente contexto de crisis político- sociosanitaria, es que el presente artículo persigue realizar una acotada descripción y análisis de algunas de las producciones académicas e institucionales chilenas enmarcadas durante la revuelta y la pandemia, con el fin de entregar luces acerca de la pregunta ¿cómo están siendo posicionadas y 
producidas las juventudes por el saber académico e institucional durante los contextos de la revuelta y la pandemia? Esto, con el objetivo de generar una reflexión en torno a los lineamientos teóricos que subsisten detrás de dichas nociones/configuraciones.

Para llevar a cabo dicho objetivo se implementó una metodología de tipo cualitativa por medio de la técnica de análisis documental (Valles, 1999), con la que se persiguió realizar un meta-análisis de la muestra seleccionada, de modo de realizar una observación (Strauss y Corbin, 2002) de los esquemas de producción juveniles de los artículos e informes seleccionados. Dicha muestra se escogió sobre la base de un universo mayor de textos, que se compuso por medio de una búsqueda en diversas plataformas de revistas indexadas y no indexadas junto con plataformas institucionales. Esta búsqueda se realizó a partir de los conceptos de «estallido social, «revuelta», «pandemia»y «juventudes en Chile». Como se mencionó con anterioridad, dichos conceptos se escogieron en virtud de realizar una revisión sucinta del estado del arte en la producción académica e institucional en el actual contexto de crisis en el que nos encontramos. De modo que se hizo una revisión de un total de 95 textos, entre artículos e informes, los cuales fueron distribuidos en dimensiones de acuerdo con las principales temáticas que abordaban. De esta forma, las dimensiones fueron: estallido social y/o revuelta, gestión del Estado en la revuelta y la pandemia, participación y acción política, impactos del Covid-19 en la población, salud psicoemocional, crisis sociosanitaria, discursos de la prensa en relación con la revuelta y la pandemia.

A partir de ello se realizó la selección de una muestra acotada de 47 textos por medio de un muestreo teórico o «muestreo motivado» (Coller, 2005: 76), que se estructuró a medida en que se fue realizando el proceso de codificación y análisis de los textos, de modo que se establecieron dos criterios de selección: uno relativo al origen de los textos, en tanto se estableció la producción nacional como atributo, y otro relativo al contexto de crisis sociopolítica sanitaria 
experimentada desde el año 2019 hasta hoy en día. De esta manera, se escogieron textos comprendidos dentro del período de octubre de 2019 hasta abril de 2021, en razón de que en dicha etapa la temática de juventudes obtuvo un mayor apogeo en los medios y en la academia, por un lado, a raíz del proceso político de la revuelta (Alé, Duarte y Miranda, 2020), y en segundo lugar, por la impronta del discurso sobre los/as jóvenes en los medios a raíz del control de la pandemia.

Por último, a los textos seleccionados se les aplicó un análisis de contenido (Díaz y Navarro, 1995; Abela, 2002) en relación con las dimensiones anteriormente mencionadas, de los cuales salieron como relevantes - y por saturación - tres categorías a partir de las cuales se estructura este trabajo: «control social», «acción colectiva»y «afectividades y salud». Dichas categorías se proponen como transversales a los tópicos abordados por las dimensiones establecidas, a la vez que presentan un carácter de contingencia y pertinencia en virtud de los criterios teóricos mencionados. Dentro de los cuales se pueden desagregar tres ejes: el proceso de articulación política que conllevó la revuelta —donde tuvo mayor relevancia la figura de los/as jóvenes - con el posterior tratamiento que el Estado desplegó en materia de control político, así también de la protesta y en seguridad respecto a las acciones de la revuelta y, finalmente, el ulterior escenario de crisis/afección que se abrió con la llegada de la pandemia. De esta forma, las categorías propuestas buscan adentrarse en las construcciones sobre lo juvenil y las juventudes desplegadas por los textos en estos tres ejes.

Finalmente, se procedió a establecer un análisis descriptivo de la producción de las nociones de juventudes que están estableciendo los textos estudiados, al tiempo que nos alimentamos de discusiones precedentes sobre juventudes respecto al carácter o lineamientos teóricos en que se insertan dichas nociones juveniles, entre ellos, Aguilera (2009), Dávila (2018), Dávila y Ghiardo (2018), Duarte (2018), y Zarzuri y Ganter (2018), debido fundamentalmente a que realizan una revisión del estado del arte de la temática de juventudes en Chile 
postdictadura, y analizan teórica y epistemológicamente la configuración de lo juvenil en dicho saber académico.

\section{CONSTRUCCIONES ACADÉMICAS SOBRE EL CONTROL SOCIAL HACIA LAS JUVENTUDES}

Desde el inicio de la Revuelta del 18-O de 2019 hasta la actual situación de la pandemia en Chile, se ha gestado una diversidad de investigaciones en el marco del análisis del control social. Dichos trabajos - para efectos de este artículo - han deambulado en tres líneas: las acciones gubernamentales tendientes al control social de la revuelta a raíz de las acciones de protesta, profundizando en los mecanismos securitarios desplegados por el Estado y los poderes judiciales para su regulación (Karmy, 2020; Richard, 2019; Pincheira 2020a; Villalobos-Ruminot, 2020), así como también los discursos criminalizadores del mismo Estado y de los medios de comunicación en relación con la revuelta y el orden público, puesto en disputa a través de las jornadas de manifestación (Alè, Duarte y Miranda, 2020; Escobar, Araya, Hernández y Duarte, 2021; González, 2021). Junto a estas líneas, se ha forjado una tercera que ha pretendido describir de modo estructural las acciones estatales referentes a la mitigación de la pandemia en términos sanitarios, sociales y económicos, haciendo el anclaje con los dispositivos de control sanitarios desplegados para disminuir los contagios (Abufhele y Jeanneret, 2020; Pincheira, 2020b; Bustos, 2020; Rettberg, 2020; Acuña, 2021). Cabe señalar que, si bien existe una investigación social que vincula el control social — de diverso signo - con las juventudes, con énfasis en aquella excluida y en conflicto (Tijoux, 1995; Goicovich, 2000; Tsukame, 2016), en la mayoría de las investigaciones trabajadas la mirada tiende a no generar una mayor reflexión sobre los sujetos en cuestión. En el marco de esta reflexión y para efectos de este apartado, nos abocaremos a las investigaciones que han elaborado análisis respecto a cómo los 
dispositivos de control sobre la revuelta y la pandemia han afectado a los jóvenes, considerando también las investigaciones antes referidas como coadyuvantes del análisis.

Como se sostuvo en esta introducción, las acciones políticas de las juventudes desde el inicio de la revuelta han sido variadas y han circulado por distintos soportes y espacios políticos. Sin embargo, las acciones políticas de las juventudes ligadas a la protesta han tenido una contracara: la acción estatal como gestión gubernamental de la protesta social. En este campo, las medidas efectuadas por los distintos dispositivos de seguridad y control del Estado trascendieron desde una regulación de la protesta social a un control social. Dicha regulación de la protesta, en especial la que se posiciona en tensión con la estructura tradicional política, ha sido la que ha estado mayormente expuesta a los discursos criminalizadores del Estado y a los mecanismos disciplinarios y sancionadores del poder judicial, los que en su conjunto se entrelazan con el discurso hegemónico de los medios de comunicación para conformar un entramado gubernamental que persiguen conducir las acciones juveniles de protesta. Para González (2021), esto no es menor, pues se ha dado en condiciones de estigma y etiquetaje social contra las juventudes que tienden a reafirmar miradas que comprenden la acción de estos desde la peligrosidad, la desviación y la amenaza. Para este autor, también el proceso de revuelta evidenció la conversación social entre generaciones que, en un encuentro inédito, ponen en riesgo a la sociedad mayor; enunciando que las élites «si bien no perdieron su poder, perdieron su autoridad» (p. 110).

Con relación a lo anterior, hay que tener en cuenta que la llegada del virus a Chile genera un escenario ideal para la acción estatal, pues posibilita restablecer el orden público arrebatado por la movilización desde el inicio de las jornadas de protestas. Para Richard (2020), por ejemplo, el contagio facilita el uso gubernamental de la pandemia para ejercer el control social de la población, inaugurando un nuevo tiempo, el de la cuarentena, la inmovilización y el estado 
de excepción. Respecto a lo anterior, para Pincheira (2020b), la gestión gubernamental de la pandemia se ha concentrado en el despliegue de tres estrategias, principalmente. Una ligada a la sanción punitiva; otra de corte disciplinar en torno al modelo de cuarentena $\mathrm{y}$, finalmente, una securitaria en torno al establecimiento de medidas estadísticas del riesgo aceptables para el funcionamiento social. En este esquema, los actores privados y públicos, y su posible articulación, son clave para la materialización de esta gestión. Bajo este contexto, se han activado una serie de mecanismos, como el despliegue de contingente policial y militar en las calles junto con el establecimiento del «toque de queda» para regular el libre desplazamiento por la ciudad. Sumado a ello, se han instalado las cuarentenas con el fin restringir y disminuir la concentración y el desplazamiento de individuos en los espacios públicos. A la vez, se ha articulado un aparataje securitario a través del uso de la tecnología como ente mediador y fiscalizador del tránsito en la ciudad, junto a ello se ha privilegiado la comunicación sobre el riesgo/contagio por medio de los mass media para mantener en permanente alerta a la población. Todo ello ha generado un barrido de las problemáticas, demandas y movimientos expuestos en la revuelta (Richard, 2020).

En razón con lo anterior, para Bustos (2020), estos dispositivos de control social han quedado reservados para frenar el impulso insurreccional de las movilizaciones tras la revuelta, en tanto que los mecanismos en materias de salud pública han perseguido una profilaxis individual: «Cada individuo debe administrar por sí mismo, y en función de su condición socioeconómica, los riesgos que implican salir a trabajar» (Bustos, 2020: 27). De este modo, los planes y medidas presentados por el Ejecutivo, al tiempo de anunciar su carácter sanitario, también revelan el interés económico como el motor de las acciones gubernamentales para paliar los efectos nocivos de la pandemia en las economías locales, en una articulación público-privada que individualiza los costes de la pandemia en la población. Las nuevas condiciones de comunicación globalizada 
acuden a reconfigurar las relaciones sociales entre los individuos, limitando los encuentros cara a cara y potenciando la mediación virtual para la socialización, lo que para Acuña (2021) genera un modelo de gobernanza globalizado que ha operado en el espacio del hogar, transformándolo en un motor de desigualdad en tanto «permite reafirmar la tendencia a concentrar a los individuos en espacios cada vez más reducidos y localizados, con la menor inversión social» (p. 135).

Si bien las investigaciones no han profundizado mayormente respecto a las afecciones del control social en específico sobre las juventudes, se puede denotar una mirada un tanto homogénea de las juventudes (Dávila, 2018; Araya, Carrasco y Olivares, 2020), debido a que estas contribuyen a generar tratamientos invisibilizadores de estas políticas en el discurso público sobre los jóvenes. Sin embargo, hay puntos de inflexión dentro de este discurrir; uno de estos es el señalado por Richard (2020) en cuanto manifiesta que, bajo el contexto de la revuelta, los/as jóvenes encarnan la denominada «primera línea», frente encargado de contrarrestar y mantener fuera del espacio de protesta a los agentes represivos del Estado, para que el resto de los convocados se manifestara. Dicha primera línea era reconocida y legitimada por la población, mientras que era penalizada por parte del Estado, quien, a su vez, criminaliza la figura de los jóvenes en tanto agentes de protesta. Con el advenimiento de la pandemia, la denominación «primera línea» es cooptada por la institucionalidad, estableciendo un viraje semántico sobre ella y adjudicándola al personal de salud, que esta vez combate al virus (Richard, 2020), despojando a los jóvenes de uno de los «hitos la revuelta».

Este proceso de borradura de las acciones de protesta, por parte del Estado, ha ido de la mano con la refundación de visiones, estereotipos y estigmas sobre los jóvenes, a quienes se asocia con el riesgo, la peligrosidad y la amenaza de contagio ante el virus, discurso que han sostenido las instituciones de salud y los mass media. Respecto a ello, Araya, Carrasco y Olivares (2020) señalan que se ha articulado un discurso individualizador sobre los/as jóvenes como foco de 
contagio, que los homogeneiza bajo una visión biologicista, por un lado, y que los posiciona como un sector peligroso para el resto de la población, por otro lado, al tener conductas de transgresión e irresponsabilidad frente a las medidas sanitarias. Esta imagen de los jóvenes como un sector de peligro sanitario ha tendido a criminalizar las prácticas y espacios asociativos de los jóvenes, estimulando su imagen disruptiva ante el orden social (Krauskopf, 2015). En estas lecturas, en consecuencia, a la vez que se modifica la imagen de los jóvenes como soporte solidario que persigue cambiar las condiciones estructurales de desigualdad del sistema, que se venía articulando a lo largo de la revuelta, quita los puentes intergeneracionales que se habían construido en las jornadas de protesta, acrecentando las miradas estigmatizadoras sobre los/as jóvenes.

Como hemos señalado, el llamado hacia las juventudes por parte del aparataje institucional en este contexto de pandemia no puede ser comprendido sin el antecedente de la revuelta social, pues muchas de las medidas soberanas y disciplinarias tienen como principal afectado las prácticas de las/as jóvenes. En este sentido, conviene señalar que con los antecedentes presentados, algunas de las investigaciones expuestas, junto con señalar que la población juvenil es el objeto de los discursos estatales que llaman a la precaución y responsabilidad, advierten sobre los nocivos efectos pandémicos a mediano y largo plazo que pueden recaer sobre las juventudes. Ello sobre la base de la consideración de una serie de datos construidos en la región latinoamericana, que los ubican como una población en alto riesgo social, incluyendo una mayor participación en situaciones de violencias y de muerte (Rettberg, 2020).

Las medidas y planes implementados por el gobierno, analizados bajo la nominación del control social, han gestionado un cambio de escenario en el imaginario colectivo sobre los jóvenes, en tanto se ha pasado de un discurso de desobediencia insurreccional a una obediencia forzada, de un discurso de acción colectiva a un discurso individualizador del autocuidado, de la apropiación de los espacios públicos para la acción colectiva al uso de la propiedad privada para el 
teletrabajo y el estudio. En cuanto a la población «juvenil», para algunos autores (Escobar Araya, Hernández y Duarte, 2021), las categorías como criminalización se vuelven las «claves de este imaginario Adulto-Estatal, para comprender la imposición de mecanismos de control y subvaloración de las prácticas que las y los jóvenes proyectan en su cotidianidad» (p. 87). Estos discursos han recaído con mayor rigurosidad sobre jóvenes, en tanto que sus espacios de socialización por excelencia — colegios, universidades, bares, espacio público, entre otroshan sido limitados (Abufhele y Jeanneret, 2020). A su vez, se les ha restringido su capacidad organizativa y potencia creadora que habían estado articulando a lo largo de la revuelta, al desarticular sus prácticas de convergencia en el espacio público.

En razón de lo anteriormente expuesto, se puede vislumbrar, tomándonos del análisis que realiza Duarte (2018) respecto a los lineamientos epistémicos con los que se ha tematizado las nociones de juventud, que dichas nociones en el ámbito del control social han deambulado en razón de una noción biologicista de las juventudes, en tanto generan una naturalización de la condición de ser joven, por un lado, la que va acompañada por los imaginarios referentes al ciclo vital, en cuanto este se desagrega en etapas evolutivas que los individuos van atravesando, siendo los jóvenes entendidos como una etapa de tránsito e incompletitud que debe ser tutelada debido a las ideas de moratoria psicosocial e integración social, las que se refuerzan a partir de los discursos posicionados en pandemia. A su vez, dicha noción va acompañada con la idea de conflictividad social como constitutiva del quehacer juvenil, en su intento por posicionarse socialmente, idea que se vislumbra en los discursos efectuados sobre las juventudes que accionaron en la revuelta, así como la noción naturalizada y reduccionista de que las acciones políticas son intrínsecas a lo juvenil. 


\section{CONSTRUCCIONES ACADÉMICAS SOBRE LA ACCIÓN COLECTIVA DE LAS JUVENTUDES}

Las investigaciones sobre acción colectiva de las juventudes en contextos de crisis social y sanitaria han tomado centralidad en el escenario académico nacional. Si bien aún es muy pronto para sistematizar la producción resultante en estos contextos - pues muchos proyectos se encuentran en proceso o en vías de publicar resultados-, ya se observa un considerable número de publicaciones sobre esta temática a nivel nacional. Sin embargo, se identifica que la producción sobre la categoría se enfoca mayormente en la revuelta y el proceso constituyente resultante del mismo, y no tanto en el contexto de la pandemia, siendo pocas las publicaciones encontradas que contemplan ambas crisis (García, 2020).

En la literatura consultada se pueden observar dos grandes ámbitos de estudios sobre acción colectiva en estos contextos, los que, por un lado, abordan las construcciones y sentidos de la acción colectiva de las y los jóvenes y, por otro, aquellos que dan cuenta de cómo se ejercen estas acciones colectivas y sus especificidades durante la crisis social y/o sanitaria.

El primer ámbito reflexiona sobre su impronta bajo distintas terminologías. Se encuentran aquí las investigaciones que abren el diálogo sobre socialización política y trayectorias juveniles (Angelcos, Roca y Cuadros, 2020), subjetividad política (Angelcos, Roca y Cuadros, 2020; Ganter y Zarzuri, 2020), cultura política (Ganter y Zarzuri, 2020) o acciones colectivas comprendidas de forma amplia en relación con entornos familiares (Gonzalez, Frigolett, Bazan y Carozzi, 2021). Estos estudios ofrecen aportes sobre el distanciamiento de lo institucional en las formas de participación, apostando por una reivindicación de la solidaridad, la cultura y la subjetividad como forma política de estar con el otro y la confianza en la capacidad de organización y transformación (Videla y Luengo, 2021). Otros autores evidencian que la experiencia de la acción colectiva en contextos de revuelta se articula en torno a una dimensión emocional 
ambivalente, no ideológica, que activa y moviliza a la acción política desde un rechazo emocional a una normalidad insoportable (Sandoval, 2021).

En el segundo ámbito se encuentran estudios que reflexionan sobre comportamiento político y acciones disruptivas (Angelcos, Roca y Cuadros, 2020), empleando diferentes categorías como repertorios de acción (Angelcos, Roca y Cuadros, 2020; Ganter y Zarzuri, 2020), acción política (Sandoval, 2021; Ganter y Zarzuri, 2020) o activismo sexopolítico (Ravelo y Duarte, 2021). También se encuentran otros trabajos que emplean categorías como participación ciudadana (Videla y Luengo, 2021; Salinas, Castellvi y Camus, 2020), competencias en ciudadanía y empoderamiento constituyente (Salinas, Castellvi y Camus, 2020) para dar cuenta de acciones colectivas en estos contextos. Como se observa, el abordaje se hace desde diferentes categorías, pero finalmente todas dan cuenta de un mismo fenómeno; si bien llama la atención su uso indistinto, ello también demuestra la heterogeneidad de formas de prácticas políticas juveniles.

Cabe destacar aquí los trabajos que comprenden la movilización como acción colectiva en relación con el uso de redes sociales presenciales y digitales para explicar el carácter de este fenómeno social masivo tanto en la revuelta, como posteriormente en la pandemia (García, 2020). Esta comprensión contempla un análisis en tres ejes: a lo interno de los colectivos, en articulación entre los colectivos movilizados, y la incorporación masiva a las movilizaciones de otros/as agentes de la ciudadanía que no pertenecían a ningún colectivo o asociación y el papel de las redes sociales en ello (García, 2020). De esta manera, en este grupo de estudios aparecen en común aquellas acciones colectivas como: participación en protestas, revueltas, cacerolazos, participación en cabildos y consultas ciudadanas, cicletadas, así como en movilizaciones masivas en la rebautizada Plaza de la Dignidad, que algunos autores destacan como revolución y despertar de un pueblo (Cuevas y Budrovich, 2021). 
Teniendo en cuenta estos dos grandes ámbitos de estudios relacionados con la acción política en períodos de crisis social y sanitaria, podemos destacar que en la mayoría de los trabajos, independientemente de los énfasis y terminología que se utilizan, existe un reconocimiento de las distintas formas de participación y accionar, así como de la diversidad de repertorios posibles encontrados durante la revuelta. En este sentido, se avanza en un debate por no privilegiar unas formas de accionar sobre otras, dejando un poco atrás las viejas discusiones sobre participación política convencional y no convencional; y reconociendo las posibilidades de actuación en espacios presenciales — como el espacio online - para articular determinadas formas de acción colectiva (Araujo, 2019; Cuevas y Budrovich, 2021; Garcés, 2020a).

Sin embargo, a pesar de lo anterior, cuando se observa la acción política de las juventudes en estos espacios, la mirada no ha sido tan diversa. Así, las investigaciones revisadas para el presente trabajo visibilizan fundamentalmente a juventudes universitarias (Angelcos, Roca y Cuadros, 2020; Salinas, Castellvi y Camus, 2020; González, Frigolett, Bazan y Carozzi, 2021), y dentro de ellas enfocan la mirada a criterios estructurales de territorio, de procedencia o a un criterio educativo-vocacional: jóvenes que proceden de barrios populares y estigmatizados de Santiago (Angelcos, Roca y Cuadros, 2020); jóvenes de cuarto semestre de la carrera de Pedagogía en Educación Básica de la Universidad de Antofagasta (Salinas, Castellvi y Camus, 2020), universidades metropolitanas (González, Frigolett, Bazan y Carozzi, 2021). Otros, sin embargo, desarrollan una mirada generacional homogénea de la juventud chilena actual (Ganter y Zarzuri, 2020) o abordan a los estudiantes secundarios de la Región Metropolitana (Videla y Luengo, 2021). De esta manera, la mayoría de los estudios tiende a repetir la tendencia de las investigaciones chilenas a visibilizar la participación de las y los jóvenes vinculados fundamentalmente con instituciones educativas, invisibilizando así a otras juventudes como las rurales, indígenas y/o sindicales que expresan otras posiciones en la estructura social 
(Dávila, 2018). No obstante, existen también esfuerzos académicos que buscan abarcar una diversidad de biografías y prácticas juveniles (Alè, Duarte y Miranda, 2021).

Por otra parte, algunas producciones académicas que dan cuenta de la acción política en contextos de crisis social y sanitaria traslucen una mirada de la juventud en clave generacional; sin embargo, en ocasiones lo hace desde una perspectiva homogénea, caracterizada por la formación de una nueva subjetividad política, que viene formándose hace algunas décadas en Chile. Ella incluye un proceso de repolitización y una transformación de las formas de acción política, alejadas de los tradicionales polos izquierda-derecha, sin líderes, apego a ideologías, estructuras ni organicidad, pero sí con un fuerte peso en lo colectivo y cultural, territorial y comunitario, enfrentada a la subjetividad neoliberal y su modo de vida (Zarzuri y Ganter, 2018). En estos trabajos las generaciones jóvenes son vistas como catalizadoras del cambio y, si bien ello no es novedad, sí se aprecia como diferenciador para Chile, ya que en los datos que aportan sincronía, convergencia y complicidad con las generaciones adultas en las demandas y agendas, muestra que el cambio en la subjetividad política no es excluyentemente generacional; si bien ellos, los y las jóvenes, son identificados como impulsores. Interesante resulta ser, sin embargo, que se identifique como uno de los principales factores detonantes de la participación en el accionar colectivo de movilizaciones y protestas — no el único- el efecto imitación y contagio de pares (Ganter y Zarzuri, 2020), poniendo en tensión la idea de un sólido cambio en la subjetividad política que permea la consistencia de las prácticas; lo que coloca a las juventudes nuevamente en matriz tradicional adultocéntrica.

Otros trabajos (Angelcos, Roca y Cuadros, 2020) —si bien centrados en grupos específicos como los universitarios que proceden de comunas capitalinas estigmatizadas y populares - logran identificar la heterogeneidad como marca fundamental de la juventud y su participación política. Así, muestran con datos 
la existencia de jóvenes que se distancian de la participación política tradicional, rechazan las formas disruptivas y violentas de la acción política que identifican con una «cultura de calle» de la cual proceden pero que rechazan; se visualizan a sí mismos sin un capital cultural para enfrentar el cambio constitucional y por tanto se muestran pesimistas con el proceso y se restan de él. Otros que, sin embargo, aun rechazando y juzgando estas prácticas como no valiosas desde un posicionamiento moral, sí se vinculan a la acción política no disruptiva como cacerolazos, manifestaciones, cabildos y asambleas territoriales, y confían en la institucionalidad como camino legítimo. Dentro de la diversidad de las juventudes identifican la existencia también de expresiones contraculturales que no necesariamente abrazan un compromiso político ni muestran interés en la revuelta; mientras otros sí han encontrado en sus prácticas culturales formas de socialización política que expresan a través de formas de solidaridad y colaboración comunitaria. Dentro de esta diversidad, también se identifican aquellos jóvenes que se vinculan directamente a las organizaciones políticas, partidos y militancias tradicionales, sin abandonar las prácticas políticas más comunitarias, barriales y/o disruptivas.

Aparecen otras publicaciones centradas en la revuelta, que se destacan por el cruce del feminismo con las demandas políticas también desde el cuestionamiento a los modos patriarcales de hacer política, a las estructuras binarias, heteronormadas y sexistas propias de la institucionalidad (Ravelo y Duarte, 2021). En este sentido, se visibilizan en las producciones académicas otras juventudes: las feministas y de disidencias sexuales (Araujo, 2019; Ravelo y Duarte, 2021). Otros trabajos logran aportar a la visibilización de estas otredades, dando cuenta del rol que tuvieron en la revuelta las juventudes trabajadoras, deudoras, pobladoras, en desempleo y en precariedad laboral, jóvenes con hijos/as, barristas o miembros de organizaciones territoriales (Araujo, 2019; Garcés, 2020b); que al igual que las juventudes vinculadas a instituciones educativas, tuvieron un papel protagónico en la revuelta por 
soportar y encarnar durante más de treinta años «tramas y tensiones» (Araujo, 2019), en varias generaciones familiares que pusieron en evidencia las grandes desigualdades estructurales por las que se salió a las calles en octubre de 2019.

Esta diversidad de juventudes le ofrece a la construcción del conocimiento distintas aristas y logra dimensionar la multiplicidad de causales por las que las y los jóvenes se hicieron presentes en la revuelta (Garcés, 2020a). Sin duda, esta diversidad de juventudes también se debe articular en las producciones sobre acción colectiva en pandemia para comprender su expresión en períodos de crisis — sociales y sanitarias - , bajo una mirada que dé cuenta de la multiplicidad de formas de expresión y repertorios, así como lo reconfigurable de estos, enriqueciendo las perspectivas de análisis.

\section{CONSTRUCCIÓN ACADÉMICAS E INSTITUCIONALES SOBRE LAS AFECTIVIDADES Y SALUD DE LAS JUVENTUDES EN PANDEMIA}

La irrupción del Covid-19 significó un importante cambio en distintos ámbitos de la vida, configurándose como un hecho social total (Robledo y Giménez, 2020; Madariaga y Oyarce, 2020) que implicó una convulsión de las relaciones sociales; lo anterior, para el caso chileno, significa también incluir el análisis de la revuelta desde su imbricación presente.

Tomando en cuenta el ámbito de las afectividades, emociones y salud mental, cabe destacar que las indagaciones - académicas e informes realizados desde programas de intervención institucionales - han focalizado la visión principalmente en los efectos que ha tenido la pandemia en las relaciones y subjetividades de los jóvenes, especialmente en sus cotidianidades y en el estado de su salud mental (INJUV, 2020; OIT, 2020; Morales, 2020; Andrades-Tobar, García, Valiente y Lucero, 2021; Larraguibel, Rojas Andrade, Halpern y Montt, 
2021). La mayoría de estas producciones tienen una mirada que tiende a focalizar las experiencias a nivel individual y con una mirada biomédica más que social, siendo débiles los nexos con los acontecimientos de la revuelta (Araujo, 2019; Madariaga y Oyarce, 2020).

Respecto a este tema, en los estudios revisados se pudieron encontrar tres dimensiones de abordaje de las relaciones, emociones y salud mental: los cambios en la vida cotidiana a partir del encierro; emociones y sintomatología derivada del contexto de encierro; y aspectos asociados a derechos que se han visto afectados por la pandemia.

A partir de lo anterior, constatamos que algunas investigaciones se han propuesto producir información primaria en torno a la salud mental en jóvenes en Chile (INJUV, 2020; OIT, 2020). Estas son de carácter cuantitativo, provenientes mayormente de encuestas y que buscan hacer un tipo de sondeo sobre la base de una tipificación por edad, género (únicamente masculino y femenino) y nivel socioeconómico, sin necesariamente cruzar estas variables ni integrar otras que podrían enriquecer el análisis. Entendemos que esta tendencia puede responder a que la irrupción de la pandemia es relativamente reciente y nos encontramos frente a un punto de inflexión para las investigaciones en torno a la salud mental en jóvenes en Chile, pero se hace necesario dar un salto cualitativo teniendo estos antecedentes, vislumbrando las proyecciones y nuevos desafíos que se presenten (Dávila, 2018; Dávila y Ghiardo, 2018).

Respecto a las variaciones en la vida cotidiana de los y las jóvenes, las medidas de aislamiento por razones de salud pública han significado un importante cambio en rutinas y vínculos afectivos que se construyen fuera del espacio doméstico, en ámbitos que son fundamentales dentro de su desarrollo psicosocial (Tobar et al., 2021). A su vez, el encierro ha significado un importante desafío para las relaciones intergeneracionales al interior de distintos grupos 
familiares en Chile, pudiendo expresarse en variados conflictos, siendo urgente poder enfrentar de una manera integral estas problemáticas.

Un punto que se ha desarrollado en las investigaciones en torno a la vida cotidiana en jóvenes en el contexto pandémico es la percepción que se construye en torno a esta situación, tensionando distintas trayectorias y certezas. Es así que en el ámbito laboral, diferentes estudios concluyen que el trabajo en jóvenes estaría viéndose aún más afectado y precarizado por la pandemia, dificultando la capacidad de ahorro y autonomía financiera a nivel individual y también como grupo familiar (INJUV, 2020; OIT, 2020). Respecto a las trayectorias educacionales, estas se han visto reconfiguradas, trasladándose al formato virtual, planteando nuevos desafíos para un aprendizaje integral y la salud mental de jóvenes en un contexto previamente caracterizado por distintas desigualdades de acceso a recursos materiales y tecnológicos, como internet y computadoras eficientes (Acuña, 2021).

Otro punto que dialoga con las experiencias y emociones en jóvenes en este contexto son la seguridad y la salud, generalizando un sentimiento de vulnerabilidad e incertidumbre en torno al virus y sus efectos, sobre la base de los altos niveles de mortalidad y contagio tanto a nivel general como en círculos más cercanos como los familiares (Tobar et al., 2021). Esta inseguridad se vería acentuada en jóvenes al ser un grupo social que se relaciona estrechamente con los nuevos medios como el internet, donde circula un alto volumen de información de diversa fuente, la cual no necesariamente está respaldada ni pasa por un filtro de veracidad, aportando a un sentimiento de incertidumbre generalizada.

El desarrollo respecto a las relaciones afectivas y efectos en la subjetividad de jóvenes ha sido débilmente trabajado en la producción académica e institucional revisada, considerando, en este sentido, el contexto y el vuelco práctico y mediático que han tenido las relaciones y experiencias de estos/as, 
sumado a las medidas de control de la pandemia en una juventud que, hasta marzo de 2021, estaba fuertemente movilizada en términos políticos, con un gran despliegue en las calles y con una agencia reconocida como relevante en términos de crítica y acción contrapolítica. Como se planteaba anteriormente, jóvenes glorificados en su rol de primera línea, criminalizados por el Estado y luego resignificados como peligrosos como foco de contagio (Araya, Carrasco y Olivares, 2020).

En este plano, son importantes las variaciones de las relaciones con otros, el paso de espacios colectivos y emergentes en el contexto de la crisis social, de la colaboración, el sentir común, el buscar espacios para hablar de la herida de la dictadura, pero también para hablar de la (re)construcción de un Chile más justo (Araujo, 2019), a una contención y aislamiento casi absoluto y totalmente abrupto. En este sentido se señalan desde algunos estudios previos a la pandemia, cómo en jóvenes y adultos dominaban sentimientos como la rabia frente a injusticias y violaciones de derechos humanos, los que se acompañaban de emociones de esperanza y encuentro con otros y otras (Araujo, 2019; Madariaga y Oyarce, 2020). Estas instancias y sentires se vieron mermados por el control del contacto social una vez que la pandemia llega al país, lo que se ve acompañado de la generación de sentimientos de miedo, angustia y desazón (Madariaga y Oyarce, 2020).

En el plano de las emociones, algunos estudios más específicos visualizan principalmente desde un enfoque biomédico los efectos afectivos y emocionales de la pandemia, mostrando la existencia de sintomatologías depresivas y ansiosa junto a emociones como «estar tristes» o «irritables», además de cambios de alimentación y sueño. También se señalan emociones como miedo y preocupación por sus familias, sensaciones acompañadas por el aislamiento, la pérdida de vínculos y estar constantemente frente a pantallas (Larraguibel, Rojas Andrade, Halpern y Montt, 2021). Específicamente en el tramo de edad entre 18 y 29 años, se realizan algunos estudios y se señala que se dan síntomas 
principalmente asociados a estrés, que son más agudos en la edad entre 15 y 19 años, seguido por los de entre 25 y 29 años, y menos en los de 20-24 años. Otro estudio complementa datos incluyendo dimensiones socioeconómicas, al mostrar que en jóvenes entre 18 y 29 años, en general de estratos bajos, se dan emociones de cansancio, aburrimiento, inquietud y agobio. Se destaca finalmente que en las mujeres existiría mayor desmotivación, tristeza, miedo y mayor cansancio (OIT, 2020; Andrades-Tobar, García, Valiente y Lucero, 2021). De igual manera, algunos jóvenes de entre 18 y 29 años señalan sentimientos o emociones que son sentidos de manera positiva, entre ellos, preocupación por otros, solidaridad y gratitud (Universidad de Chile, 2020).

Cabe preguntarse, desde un prisma relacional de los efectos de esta crisis, cómo las emociones - y su reflejo en salud mental a nivel de síntomas y también en relaciones - van produciendo encuentros y desencuentros con otros, el verse similar o distintos con otros y cómo se visualiza a las y los jóvenes en esto, quienes han estado fuertemente involucrados en la revuelta, así como también fuertemente cuestionados en la pandemia por posibles «irresponsabilidades» frente a los cuidados. Ahmed $(2004,2015)$ plantea que son las emociones producidas por impresiones que los otros nos dejan, tanto en el presente como registros pasados - las que generan cercanía o lejanía hacia otros. Estas emociones no tienen una preponderancia psicológica, sino que obedecen a una lógica social y cultural, es decir, se producen en ciertos contextos y generan ciertos efectos, son performativas y narrativas (Butler en Ahmed, 2015). Las personas se acercan a quienes aman, y por tanto con quienes comparten similitudes, y se alejan o rechazan a quienes son vistos como diferentes. En esta lógica, llaman la atención los efectos, no tan solo personales que la crisis social y sanitaria genera en jóvenes y adultos, sino aquellos efectos colectivos, los reconocimientos, los rechazos, los encuentros y desencuentros, donde a los jóvenes se les busca ordenar constantemente en el juego social (Duarte, 2018), o 
se les enuncia como chivos expiatorios; o se les ama y glorifica o se les expulsa, se les critica o criminaliza.

En relación con los derechos, la información revisada evidencia que la exposición a situaciones dentro de la crisis social sanitaria amenaza derechos básicos como alimentación, salud, educación y también derechos asociados a actividades de esparcimiento y ocio, todo esto a través de la limitación de movimiento, y una disminución de participación en el debate público. Se plantea cómo a nivel internacional se ha visualizado un colapso en temas de derechos, sobre todo en NNJ, considerando que muchos de ellos/as dependen de adultos, lo que invisibiliza sus necesidades. Se plantea la necesidad de considerar acciones que resguarden sus derechos y que consideren la propia voz de estos actores (Morales, 2020; INJUV, 2020).

El análisis permite afirmar que la vida cotidiana y sus efectos en salud mental se visualiza desde una perspectiva principalmente individual, homogénea, biomédica, y débilmente colectiva, interseccional y temporal. Podemos igualmente dar cuenta de que se habla de efectos a nivel de síntomas, así como también de trayectorias laborales o educativas, pero se habla débilmente de lo subjetivo y el bienestar o malestar que se genera desde la escasez de espacios compartidos con otros. También está ausente un análisis que considere los efectos sobre diversas juventudes y sus subjetividades, es decir, cómo «lo situado» de cada joven en cuanto a lugar geográfico rural-urbano, género, edad, adscripción étnica o situación migrante genera una vivencia diferente respecto de los discursos y políticas asociadas al contexto social pandémico, con experiencias personales y relacionales en torno a ello. Además, es finalmente notoria la perspectiva temporal que no enlaza efectos subjetivos, de experiencia cotidiana con la crisis de la revuelta previa al Covid-19. 


\section{REFLEXIONES DE SALIDA}

La producción de conocimiento respecto a las juventudes en el actual momento de crisis se encuentra dispersa, fragmentada y en proliferación, asunto que se inscribe en una tendencia en los estudios en juventudes y la posibilidad del campo (Aguilera, 2009; Dávila, 2018). En este contexto, las diferentes y desiguales condiciones de hacerse «joven» y sus repertorios de acción colectiva son objetos de investigación múltiple, cubriendo o no determinadas aristas y procesos. A partir de esta revisión pudimos percatarnos cómo algunas de estas elaboraciones académicas y científicas tienden a subsumir el todo en una parte, a homogeneizar las juventudes incluyendo la marcación de variables discretas (edad y sexo, principalmente). Así mismo, otro grupo importante de estudios, acercándose a las experiencias juveniles, tematiza sus problemáticas y agrupamientos, la mayoría de las veces fundamentados en atributos asociados a la diversidad juvenil, en clave estructural (Duarte, 2018) o cultural (Zarzuri y Ganter, 2018). Finalmente, un último grupo releva las relaciones de poder acompañada de algunos efectos y tensiones que la actual situación de crisis proyecta sobre las poblaciones y, con un menor detalle investigativo, sobre lo que acontece con las juventudes.

Sin pretensiones de cubrir estas investigaciones con un manto de nuevas reflexiones, puntos débiles o intentar abrir un itinerario sobre futuras investigaciones en el amplio campo de los estudios en juventudes, creemos necesario apuntar a determinadas coordenadas analíticas que consideramos pertinentes para obtener una construcción de conocimiento calibrada en este particular contexto de crisis. Entre estas categorías, la interseccionalidad (Marcial, 2018), relacionalidad (Aguilera, 2009) y perspectiva generacional (Álvarez, 2018) resultan clave. Respecto a la revisión hecha, un primer asunto que considerar, y que algunas investigaciones ponen en relieve, es la condición multifactorial de las juventudes, imbricadas a determinados contextos; y por ende a particulares trayectorias, como también disposiciones sociales. En razón de 
ello, desnaturalizar la condición de juventud, al tiempo que historizar sus prácticas y relaciones (Duarte, 2018), son aproximaciones necesarias. En este sentido, respecto al corolario de control social, las reflexiones apuntan a analizar los vínculos que poseen las prácticas y discursos del Estado con estrategias de dominación y regulación sobre la población. De otro lado, las pocas investigaciones que analizan el lugar de las juventudes, si bien son cautas en no cosificar su «objeto de estudio», sí han mantenido una tendencia a homologar los dispositivos de control social con una única construcción de juventud, faltando producción de conocimiento sobre aquellas juventudes que no están incluidas en el entramado hegemónico del imaginario de control y etiquetaje social; condiciones interseccionales como juventudes rurales o de élites quedan invisibilizadas, mermando el campo comprensivo (Dávila, 2018).

Por otro lado, los diversos estudios referidos a acción colectiva en contexto de crisis sociosanitaria tienden a replicar una imagen estática de la juventud que en ciertas ocasiones impiden rastrear la presencia relacional de los demás entramados generacionales, reduciendo el análisis explicativo a una posición de juventud «contenida en imágenes esencialistas respecto a su accionar político que por intentar superar la visión adultocéntrica, reproducen una modalidad positiva de la misma» (Duarte, 2018). Sin embargo, lo anterior es contrarrestado cuando se emplea una imagen activa de las actorías juveniles, es decir, unas acciones colectivas con capacidad de ejercicio de poder, incluyendo horizontes políticos (Duarte, 2011). En este plano, es de relevancia incluir en los análisis que los diversos agenciamientos juveniles portan con marcas de politicidad interesantes de indagar; es decir, creemos necesario un abordaje que ubica las condiciones juveniles también como productoras, reapropiadoras y abiertas a los procesos de identificación (Aguilera, 2009) situados. En esta misma línea, destacamos las insistencias de algunos autores (Zarzuri y Ganter, 2018; Duarte, 2019) por promover una crítica epistémica a los enfoques binarios que, utilizando coordenadas exógenas al juego de relaciones que efectúan los actores 
sociales, constriñen los entendimientos de las subjetividades juveniles en pares de oposición.

De la última categoría trabajada en esta investigación, podemos identificar cómo una cantidad importante de estas investigaciones contribuye a reificar un entendimiento clásico de juventud; sea clasificando por grupos de edad o posicionando el componente biológico de las personas jóvenes, estas construcciones de conocimientos tienen una utilidad pragmática, ligada a las políticas públicas, en este caso de salud mental, por lo que la conversación epistémica sobre las juventudes queda en suspenso (Dávila, 2018). Por otro lado, nos encontramos con una consideración homogénea de juventud que, en clave biomédica, refiere de modo abstracto a las emociones manifestadas, sin mediar o poner atención respecto a las condiciones de posibilidad en la producción de aquellos afectos. Siendo así, una cuestión investigativa a ampliar se relaciona con generar «objetos de investigación» que problematicen la interseccionalidad de las actorías generacionales y la liminalidad de sus prácticas (Marcial, 2018), como un modo de acercamiento metodológico y teórico no solo en virtud de una representatividad estadística, sino también de una riqueza heurística de las heterogeneidades juveniles.

Finalmente, consideramos de relevancia epistémica pensar sobre las posibilidades y limitaciones para los estudios sociales que efectúa este momento excepcional acentuado por la pandemia, teniendo en consideración las disminuidas chances de acción investigativa (temporales, espaciales, presupuestarias). Esto, si bien puede ser un resultante esperado dadas las medidas de aislamiento y contención implementadas, llama la atención en tanto que un ámbito de acción colectiva relevado como significativo durante la revuelta, como por ejemplo las redes de solidaridad, el apoyo barrial y el tejido de redes virtuales para el apoyo territorial y la movilización política, no solo continuaron sino que se potenciaron con la pandemia, y muchas de estas han tenido a las y los jóvenes como actores protagónicos. Queda inevitablemente la pregunta de si esta menor 
presencia de miradas académicas a la acción colectiva juvenil durante la pandemia se debe a los efectos de las medidas de aislamiento o si tiene en su trasfondo la expresión de estereotipos o imaginarios sociales que encadenan la acción juvenil a las acciones disruptivas, y no a aquellas de colaboración y fortalecimiento de redes comunitarias para el bien común.

RECIBIDO: 30 DE JUNIO DE 2021 ACEPTADO: 31 DE AGOSTO DE 2021

\section{BIBLIOGRAFÍA}

ABELA, J. (2002). Las técnicas de análisis de contenido: una revisión actualizada. Recuperado de: https://www.academia.edu/download/54901527/borra.pdf

Abufhele, M. y Jeanneret, V. (2020). Puertas adentro: la otra cara de la pandemia. Revista chilena de Pediatría, 91(3), 319-321.

ACUÑA, M. (2021). América Latina. Entre la nueva realidad y las viejas desigualdades. Telos: Revista de Estudios Interdisciplinarios en Ciencias Sociales, 23(1), 129-140.

Aguilera, O. (2009). Los estudios sobre juventud en Chile: Coordenadas para un estado del arte. Última Década, 17(31), 109-127.

AHMED, S. (2015). La politica cultural de las emociones. Universidad Nacional Autónoma de México. Centro de Investigaciones y Estudios de Género. . (2004). Collective Feelings. Theory, Culture \& Society 2004 (SAGE, London, Thousand Oaks and New Delhi), 21(2), 25-42.

ÁlvArEZ, C. (2018). La perspectiva generacional en los estudios de juventud: enfoques, diálogos y desafíos. Última Década, 26(50), 40-60.

Alè, S., DuArte, K. y Miranda, D. (2021). Saltar el torniquete. Reflexiones desde las juventudes de octubre. Santiago de Chile: Fondo de Cultura Económica.

Andrades-Tobar, M., García, F., Valiente, C. y Lucero, C. (2021). Predictores de síntomas de ansiedad, depresión y estrés a partir del brote epidémico de COVID-19. Revista de Psicopatología y Psicología Clínica, 26(1),13-22. https://doi.org/10.5944/rppc.28090 
Angelcos, N., RocA, A. y CuAdros, E. (2020). Juventudes populares: decencia, contracultura y militancia en el Estallido Social de Octubre. Última Década, 54, 41-68.

Araujo, K. (2019). Hilos tensados: para leer el octubre chileno. Revista SulAmericana de Psicología, 8(1), 153-158. https://doi.org/10.29344/2318650x.1.2478

Araya, C., Carrasco, P. y Olivares J. (2020). Reflexiones sobre la visibilización de lo juvenil por la prensa escrita chilena, en contexto de Pandemia. Última Década, 28(53), 5-39.

Bustos, G. (2020). Pandemia neoliberal, Covid-19 y control social autoadministrado. Escrituras en cuarentena, capitalismo, contagio y políticas de muerte. Revista Disenso, 1(1), 25-35.

Cuevas, H. y Budrovich, J. (2021). ¿Revolución, revuelta, despertar de un pueblo o «estallido social»? A un año de la crisis de octubre de 2019 en Chile.Revista F@ro, 2, 159-181.

Coller, X. (2005). Estudio de Casos. Cuadernos Metodológicos No 30. España: Centro de Investigaciones Sociológicas.

DÁvila León, O. y GHiardo Soto, F. (2019). Trayectorias sociales como enfoque para analizar juventudes. Última Década, 26(50), 23-39.

Díaz, C. y NaVArro, P. (1995). Análisis de contenido. En J. M. Delgado y J. GUTIÉRREZ (eds.), Métodos y técnicas cualitativas de investigación en ciencias sociales (pp. 177-224). Madrid: Síntesis.

DuARTE, K. (2019). Trastrocaciones adultocéntricas y criterios políticos para la igualdad generacional. En K. DuARTE, N. HeRnÁNDEZ y Y. PALENZUELA, Juventudes en Chile. Miradas de jóvenes que investigan (volumen 2). Santiago de Chile: Social Ediciones.

. (2018a). Investigación social chilena en juventudes. El caso de la revista Última Década. Última Década, 26(50), 124-154.

. (2018b). Última Década como una revista espejo del campo de estudios en juventudes. Entrevista a Óscar Dávila León. Última Década, 26(50), 9-19.

Escobar, S., Araya, C., Hernádez, N. y Duarte, K. (2021). Construcción social de la participación juvenil: imaginarios adultos y miradas desde estudiantes secundarios. En Problemáticas y desafios de las juventudes en Chile. Evidencias desde las Encuestas Nacionales de Juventud (pp. 66-93). Santiago de Chile: INJUV.

GANTER, R. y ZARZURI, R. (2020). Rapsodia para una revuelta social: retazos narrativos y expresiones generacionales del 18-O en el Chile actual. Universum, 35(1), 74-103. 
GARCÉS, M. (2020a). Estallido social en el Chile neoliberal II. Represión, agenda social y la presión social que no cesa. En Conversatorio con el historiador Mario Garcés: «Estallido social en el Chile neoliberal». Recuperado de: http://www.epes.cl/wp/wp-content/uploads/2020/01/Estallido-socialII.pdf

. (2020b). Estallido social y una nueva Constitución para Chile. Santiago de Chile: LOM Ediciones.

GARCÍA, M. O. (2020). Redes sociales y acción colectiva: observando el estallido social y la Pandemia. F@ro: Revista Teórica del Departamento de Ciencias de la Comunicación y de la Información, 2(32), 30-66.

Goicovic Donoso, I. (2000). Del control social a la política social. La conflictiva relación entre los jóvenes populares y el Estado en la historia de Chile. Última Década, 8(12), 103-123.

GONZÁLEZ, Y. (2021). ¿Una «convulsión generacional»? Jóvenes, etiquetaje y estigma en la rebelión de octubre. Última Década, 28(54), 95-113.

GonzÁlez, R., Frigolett, C., Bazan, C. y Carozzi, P. (2021). Participación en acciones colectivas de los jóvenes en Chile: el rol de las normas familiares e impacto del estallido social. En S. AlÈ, K. DuARTE y D. MirandA, Saltar el torniquete. Reflexiones desde las juventudes de octubre (pp. 64-69). Santiago de Chile: Fondo de Cultura Económica.

INJUV. (2020). Sondeo Salud Mental en Pandemia COVID (población general 15 a 59 años). Recuperado de: https://www.injuv.gob.cl/sites/default/files/20200810_sondeo_salud_me ntal_covid_2020.pdf

Karmy, R. (2019). La Revuelta. Bordes, Revista de Politica, Derecho y Sociedad, 4(15), 35-49.

KRAUSKOPF, D. (2015). Los marcadores de juventud: la complejidad de las edades. Última Década, (42), 115-128.

Larraguibel, M., Rojas-Andrade, R., Halpern, M. y Elena, M. (2021). Impacto de la Pandemia por COVID-19 en la Salud Mental de Preescolares y Escolares en Chile. Juventudes en tiempos de Pandemia. Margen: Revista de Trabajo Social y Ciencias Sociales, 97(12).

Madariaga, C. y Oyarce, A. M. (2020). Pandemia por COVID-19: Un hecho social total. Sus efectos sobre la salud mental de los chilenos. Ensayos sobre la pandemia Covid 19. Revista Chilena de Salud Pública, 13-29. https://doi:10.5354/0719-5281.2020.60371.

MARCIAL VÁzQuez, R. (2018). Fronteras juveniles y delito. Última Década, 26(50), 180-197. 
Morales, C. (2020). Salud mental de los niños, niñas y adolescentes en situación de confinamiento. Revista Anales, Séptima Serie (1), 303-318.

OIT. (2020). Los jóvenes y la Covid-19: Efectos en los empleos, la educación, los derechos y el bienestar mental. Recuperado de: https:/www.decentjobsforyouth.org/wordpress/wpcontent/uploads/2020/08/Los-j\%C3\%B3venes-y-la-Pandemia-COVID19_Informe-SP.pdf

PAlenzuela, Y. (2018). Participación social, Juventudes y Redes sociales virtuales: Rutas transitadas, rutas posibles. Última Década, 48, 3-34.

PINCHEIRA, I. (2020a). Procesar la protesta: entre la potencia afirmativa de las organizaciones sociales y el devenir punitivo del Estado chileno. Estructuras en cuarentena, capitalismo, contagio y políticas de muerte. Revista Disenso, 1(1), 103-110.

. (2020b). Expulsar, disciplinar y segurizar: el gobierno del Covid-19 en Chile. Hybris. Revista de Filosofía, 11, 39-54.

RAVElo, M. y DuARTE, K. (2021). Anunciando primaveras: activismo sexopolítico juvenil. En S. Alè, K. Duarte y D. Miranda, Saltar el torniquete. Reflexiones desde las juventudes de octubre (pp. 73-77). Santiago de Chile: Fondo de Cultura Económica.

Rettberg, A. (2020). Violencia en América Latina hoy: manifestaciones e impactos. Revista de Estudios Sociales, 73, 2-17.

RICHARD, N. (2000). Del descontrol de la revuelta al control de la pandemia. Revista Anales, Séptima serie (17), 422-436.

Robledo, S. y Giménez, A. (2020). Juventudes en tiempos de pandemia. Margen: Revista de Trabajo Social y Ciencias Sociales, 97, 1-5.

Salinas Valdés, J. J., Castellví Matta, J. y Camus Galleguillos, P. (2020). ¡Chile despertó! Una investigación-acción en formación ciudadana de futuros docentes durante el estallido social. Sophia Austral, (26), 325-347. https://doi.org/10.4067/s0719-56052020000200325

SANDOVAL, J. (2021). Acontecimiento y ambivalencia emocional: la experiencia de jóvenes de Valparaíso en la revuelta social. En S. ALÈ, K. DUARTE y D. Miranda, Saltar el torniquete. Reflexiones desde las juventudes de octubre (pp. 145-149). Santiago de Chile: Fondo de Cultura Económica.

Strauss, A. y Corbin, J. (2002). Bases de la investigación cualitativa. Técnicas y procedimientos para desarrollar la teoría fundamentada. Antioquia: Contus.

TiJouX, M. (1995). Jóvenes pobres en Chile: nadando en la modernidad y la exclusión. Última Década, 3(3), 12-21. 
Tobar, M. A., García, F. E., Ponce, P. C., Ots, C. V. y Lucero, C. (2021). Predictores de síntomas de ansiedad, depresión y estrés a partir del brote epidémico de COVID-19. Revista de Psicopatología y Psicología Clínica, 26(1), 13-22.

TSUKAME, A. (2016). El rol de los medios de comunicación en la construcción de discursos en la «guerra contra la delincuencia juvenil» en Chile (19902016). Polis, 15(44), 181-201.

Universidad de Chile, Instituto Milenio para la InVestigación de IMPERFECCIONES DE MERCADO y POLÍTICAS PÚBLICAS y UNESCO. (2020). Proyecto Vida en Pandemia: para un aprendizaje social de impactos y respuestas a la Crisis en la vida cotidiana. Estudio longitudinal sobre la vida cotidiana en la Crisis del Covid-19. Recuperado de: https://www.uchile.cl/documentos/vida-en-pandemia-informe-1aimpacto-economico_166860_0_2718.pdf

VALLeS, M. (1999). Técnicas cualitativas de investigación social. Reflexión metodológica y práctica profesional. Recuperado de: https://www.academia.edu/download/33788609/606860591.IT_Valles_T ecnicas_cualitativas.pdf

Videla, D. y Luengo, P. (2021). Participación ciudadana escolar en una sociedad desigual: creencias de adolescentes chilenos en cabildos postestallido social 2019. En S. ALĖ, K. DuARTE y D. MirandA, Saltar el torniquete. Reflexiones desde las juventudes de octubre (pp. 94-104). Santiago de Chile: Fondo de Cultura Económica.

Villalobos-Ruminot, S. (2020). Virus, Revueltas, Capital. Recuperado de: https://diecisiete.org/expediente/virus-revueltas-capital/

ZARZURI, R. y GANTER, R. (2019). Giro cultural y estudios de juventud en el Chile contemporáneo: crisis de hegemonía, mediaciones y desafíos de una propuesta. Última Década, 26(50), 61-88. 